\title{
Supply Chain Orchestration Leveraging on MNC Networks and Local Resources: Approach Strategies
}

\author{
Zhengping Li' ${ }^{1}$ Robert De Souza ${ }^{2}$, Mark Goh ${ }^{3}$ \\ ${ }^{1}$ The Logistics Academy, China Federation of Logistics and Purchasing, Beijing, China \\ ${ }^{2}$ The Logistics Institute-Asia Pacific, National University of Singapore, Singapore \\ ${ }^{3}$ School of Business IT and Logistics and Platform Technologies Research Institute, RMTI University, Melbourne, \\ Australia \\ Email: zhengpingl@yahoo.com,rdesouza@nus.edu.sg,mark.goh@rmit.edu.au
}

Received 30 April 2016; accepted 23 July 2016; published 26 July 2016

Copyright (C) 2016 by authors and Scientific Research Publishing Inc.

This work is licensed under the Creative Commons Attribution International License (CC BY). http://creativecommons.org/licenses/by/4.0/

c) (i) Open Access

\begin{abstract}
Competition is becoming more global and is between the networks of businesses rather than between the firms. Operating in such an increasing networked environment, companies have to innovate their business, either be orchestrators or be orchestrated. This exploratory paper proposes an overarching Supply Chain Orchestration (SCO) framework which leverages on the capabilities of the MNC's networks and the local Logistics Service Providers (LSPs) at a strategic level. This framework comprises integrated components including orchestrated Supply Chain Network (SCN), the relationship model of the actors, a "Win-for-All" pro-orchestration model, and the collaboration platform for the LSPs. Specifically, the paper proposes a practical approach for upgrading the local industry through a virtuous model whereby the MNCs, LSPs, and government agencies collaborate to create a pro-orchestration environment for greater value adding. Using a semi-structured interview approach, key players across the logistics sector in Singapore were interviewed. The approach strategies for realizing this orchestration are investigated and the implications are discussed through a few application scenarios.
\end{abstract}

\section{Keywords}

Business Model Innovation, Supply Chain Management, Business Transformation, Orchestration

\section{Introduction}

Uncertainty and volatility abound in the marketplace. The business environment is becoming more dynamic with diverse demands and products. Multinational Corporations (MNCs) seek to build competitive strength in

How to cite this paper: Li, Z.P., De Souza, R. and Goh, M. (2016) Supply Chain Orchestration Leveraging on MNC Networks and Local Resources: Approach Strategies. Journal of Service Science and Management, 9, 303-319. 
the marketplace through flexible, reliable, and responsive supply chains. At the same time, under pressure from cost, uncertain demand, and shorter PLCs, firms outsource their needs to reputable actors who have extended the SCN. There is now a call for asset-light, orchestrated, and customer-centric supply chains [1] [2].

Orchestration is the automated arrangement, coordination, and management of complex systems, middleware, and services [3]. This concept has been applied to the supply chain in recent years due to the increasing complexity and scale in SCNs. An orchestrator is like the conductor in a symphony and the firms being orchestrated are like the members of a symphony. Hinterhuber [4] defined the orchestrator as a firm or a set of firms, which coordinates the activities of a wide array of partner companies and relates to them effectively. It is normally a dominant organization that searches for and selects partners to be pulled in for a particular business opportunity [5]. Under an orchestration scenario, supply chains have more flexible and scalable structures and better resource availability to handle the dynamics, and hence are more sustainable for growth.

While an orchestrator may not always own the production and logistics resources for supply chain operations, the value of the orchestrator is on being an architect, designing, coordinating, and managing the network. The key players of a supply chain seek to be orchestrators who then define the parameters for supply chain operations and create global networks that respond to consumer needs. Several factors influence orchestration.

The first driver is the outsourcing of non-core business. As firms focus on their core business, they are now more willing to outsource commoditized and lower value-added activities such as transportation, packing, labeling, and assembling to third party LSPs who can pool resources with greater economies of scale. Outsourcing has become a basic strategy to align supply chain players, and it is seen as a tactic to manage service and cost [6]. The new terrain is the network in a flat world and this suggests that the capability to orchestrate a complex network with multiple products, resources, functions, and organizations is key for supply chain actors.

Next, Product Life Cycles (PLC) are becoming shorter and this has made it an imperative to orchestrate supply chain activities better. The rapid change in technology and uncertain demand tend to lead to more volatile markets whereby a product can be obsolete almost as soon as it reaches the market. The shortening of PLCs forces supply chains to be more flexible and scalable to reduce the inherent risk of demand uncertainty. In addition, shorter life cycles demand faster speed to market - the time taken from design, procurement, manufacturing, and assembly to end market. Orchestration is thus needed to better manage the cycle time of a supply chain.

Third, the consolidation of demand and supply is an important driver for orchestration. Customers are growing bigger in size but fewer in number, and they are becoming more powerful and demanding too. They tend to reduce their supply bases: they want to do business with fewer suppliers albeit on a longer-term basis. The successful firms will be those who recognize these trends and seek strategies to form closer relationships with key accounts. Such strategies focus on seeking innovative ways to consolidate rather than to be "horizontal" [7].

The next driver is the need for flexibility in a supply chain. MNCs, being more structured are slower and more formalistic [8], and hence are often slow adapters given their structural inflexibility. However, firms in the emerging markets possess the advantages of speed and flexibility. These firms will exert pressure and steal market share from the MNC.

The fact that supply chains are more networked is also a driver. With better ICT, communication and dealings between business and individuals have become more convenient and cheaper. Firms find it easier to deploy their business globally by integrating their products, resources and knowledge into SCNs. The development of new technologies provides the opportunity to make better use of the network effect which exists when adding another element provides greater positive externality to the network [9]. Firms can enhance their resource value by joining such networks. Particularly, the Smaller Firms (SMEs) can benefit commercially if they join with reputable service providers.

Therefore, orchestration has become important in Supply Chain Management (SCM) and is a new paradigm of creating value through networking and integration. Given the increased complexity and interdependency within a supply chain, a firm must orchestrate or be orchestrated. An MNC may lose competitive advantage if it cannot orchestrate well to identify the value and integrate resources. For the SME, being a part of an orchestration network could help them to explore new opportunities and improve resource usage. This paper proposes a framework for MNCs and LSPs to achieve SCO by leveraging on their networks and resources.

The paper is organized as follows. Section 1 examines the drivers for SCO. Section 2 reviews the extant research on orchestration. In Section 3, the research method involves semi-structured interviews with firms based in Singapore. In Section 4, a framework for orchestration leveraging on the MNC network and the LSP's re- 
sources is presented and the main features of the orchestration model are discussed. Section 5 elaborates the approach strategies to realizing SCO. Section 6 discusses the application potential and benefits of the framework. Section 7 concludes.

\section{Literature Review}

SCO seeks for value creation and is related to the areas of resource integration, cost efficiency, and also lighter assets in supply chains.

\subsection{SCO for Value Creation}

Value creation and objective alignment are important reasons for SCO. Value chain orchestration can be defined as a way to capture and create value by structuring, coordinating and integrating the activities of erstwhile disparate markets, and relating these activities effectively to in-house operations so as to develop a network of activities that create new markets [4]. From the case studies on the agrochemical and biotech industries, Hinterhuber concludes that orchestrating an extended network of diverse partner companies improves overall performance.

Supply chain development has undergone the phases of functional excellence, internal integration, enterprise collaboration, and is now at a new stage-SCO. Among these stages, orchestration is the most advanced [10]. In this stage, the strategies and operations of the firms are guided by common objectives. Effective network orchestration requires a balance between the empowerment of customers, suppliers, and entrepreneurial managers, and building value from integrating more than from specialization [11]. While the traditional focus of core competency has been at the firm level, the rise of the networked organization requires firms to adopt a broader view. Success is based less on the competencies (resource capability) of the firm than who it can connect to.

Gereffi et al. [12] provide a framework for governance patterns in global value chains, drawing on three streams of literature, transaction cost economics, production networks, and technological capability and firmlevel learning, to identify three key variables that determine how global value chains are governed. These are: 1) transaction complexity; 2) the ability to codify transactions; and 3) supply-base capability. Their work generates five models for global value chain governance-hierarchy, captive, relational, modular, and market—which range from high to low levels of explicit coordination and power asymmetry. They provided theoretical justifications for the occurrence of these patterns and highlighted the dynamic and overlapping nature of global value chain governance using four industry case studies: apparel, bicycles, horticulture, and electronics.

There are also studies on applying SCO in industry. Through a case in the repairs and emergency services industry, Rodon et al. [13] explore the existing and new functions attributed to orchestrators in the ICT-enabled business network, and examined the effects of the orchestrators' actions and decisions on the network of relationships and performance and indicated that business network orchestrators must act as integrators to leverage on the benefits of using ICT to support the business network relationships and processes. Van der Vorst et al. [14] propose a typology of orchestration concepts using the Dutch pot plant sector, which was trying to develop new marketing channels, and diversify the products and services, to maintain their international position. Nalla et al. [15] investigate Olam International, a global network orchestrator of agrifood products, to show the relevance of orchestration in the agrifood network. The capabilities that enable Olam International to orchestrate are discussed.

The emerging role of third-party logistics providers (3PLs) as orchestrators has been investigated by Zacharia et al. [16] who found that the connectivity and communication requirements of leading supply chains have created new roles for the 3PLs, who have evolved from providing logistics capabilities to become orchestrators of supply chains who can create and sustain a competitive advantage. They use resource-based theory, network theory, and transaction cost economics to develop a model with several propositions and interviewed executives from leading 3PLs to validate their model.

There is also work on building the competitive advantage of industry clusters related to orchestration, emphasizing on the local determinants of competitiveness. Scott [17] suggested that globalization reinforces the role of local factors in competitive advantage. Porter and Wayland [18] emphasize the role of clustering in achieving competitive advantage, which is derived from a constellation of local factors that sustain the dynamism of leading firms, stressing the importance of local rivalry and supplier networks. Clearly, while the literature provides exemplars on SCO, they show that the objective of the orchestration is to achieve value-creation and alignment 
through better resource management and collaboration.

\subsection{Outsourcing and Asset-Light Supply Chain}

SCO is related to outsourcing as it aims to manage and synergize outsourcing by controlling supply chain cost and risk. Since the 1970s, many firms have foregone vertical integration and preferred to engage in a variety of inter-firm agreements. Such arrangements take on many forms, from outsourcing agreements, strategic alliances, and equity joint ventures to reciprocal shareholdings. The advantages of risk sharing, increased organizational competencies, access to new markets, and the possibility of inter-organizational learning are cited as reasons for this development [4]. An example is Li \& Fung, a trading company which became an orchestrator with an extensive network of partners in 40 countries [19].

Supply chain outsourcing denotes a specially defined contractual relationship, which requires service providers to meet different performance criteria determined by the buying organization [20]. In future, such LSPs can be classified by their problem solving and customer adaptation abilities [21] and the LSPs can be cataloged into three types based on their roles in outsourcing and integration: Basic LSPs who provide standard and traditional services such as parts manufacturing, warehousing and transportation; Integrated LSPs who provide value-added services and at least two standard services; and supply chain solution providers (4PL) with higher problem solving and adaptation capabilities with deeper integration to the customers.

In addition, firms need resources to sustainably survive and to reduce environmental uncertainty. However, it is necessary to differentiate the critical resources to be maintained internally and those resources to be outsourced. Yilmaz \& Bedük [22] studied the impact of outsourcing from the resource dependence theory and argue that firms outsource to focus on their core competence, so as to use the resources effectively to achieve their ultimate objectives and thus facilitate access to strategic resources for themselves.

As outsourcing serves to lower cost [23], it offers immediate benefits by enabling access to low-cost organizations which have more efficient and cheaper technology and information to accomplish the task. Outsourcing also reduces the need to invest in resources and talent. Hence, it reduces the need for fixed investment [24], leading to an asset-light supply chain. A frequent question is thus what activities should be outsourced to what type of service providers. Hsiao et al. [25] try to answer the question by investigating the outsourcing decision from three streams: transaction cost view, resource-based view, and SCM. They used case studies to build a conceptual framework for three levels of logistics outsourcing in the food SCN, namely execution, value-adding, and planning. They show that the degree of logistics outsourcing depends on the logistics strategy, supply chain complexity, asset specificity, transaction uncertainties, and core activity analysis. About $70 \%$ of the electronics manufacturers and retailers view the size and scope of a firm as antecedents for outsourcing. Orchestrating a supply chain with outsourcing arrangements considering inter-firm relationship, core competency, cost, firm size, integration, collaboration, and agility is an imperative for success, and effective orchestration capabilities are needed.

\subsection{Resource Dependency Management and Orchestration}

Orchestrating a supply chain is mainly on coordinating and managing the dependency of resources and capabilities of the firms in the chain [26]. To control the critical resources, an orchestrator needs to manage the resource dependencies and exploit a partner's resources. The resource dependence theory posits that firms cannot survive alone and a firm will enter into a relationship with the environment to extract labor, materials and equipment [22]. However, we do not know how a firm has resource availability to handle the demand dynamics without owning the resource.

Firms often want to achieve three objectives based on resource dependency [27]: 1) to hold on to and own critical resources; 2) to be self-sufficient in the future, and 3) dominate the market. However, it is not clear how a firm can be flexible in handling supply chain dynamics with little or no assets.

SCO harnesses external resources to achieve better control of the critical resources. As other firms may control the critical resources, any orchestration must consider supply from multiple sources. Strategies such as supplier redundancy, joint investments with suppliers, contract management of the suppliers can be used to reduce the resource dependency [22].

In the long run, risk management is critical to SCO. Supply chain uncertainty exist in many forms, such as demand and supply uncertainties, environment and internal disruptions [28] [29]. An effective orchestration 
framework must be designed to handle these uncertainties to improve the reliability of the supply chain. According to the resource dependence theory, there is a direct relation between owning the resources and power [30]. Put simply, a firm that has the control of critical resources can be the orchestrator for the network.

\subsection{Transaction Cost and Orchestration}

Transaction cost efficiency, an important consideration in SCO, is related to coordination cost and supply chain governance model. Coordination theory defines coordination as the managing of dependencies between activities. One dimension of the dependency typology involves the type of objects in the dependency [31]. Thus, the main concerns of supply chain coordination are in the customer related tasks and the resources used to accomplish the tasks. Liand Kumar [32] propose an approach to model supply chain dependency on task-to-task, taskto-resources, and resource-to-resource to minimize the coordination cost.

Transaction cost theory offers a powerful conceptual framework on outsourcing which refers to the make or buy decision in a firm [33]. Firms need to decide by doing a cost comparison between the options of performing the specific activity within their own organizations and getting it from a supplier. What needs addressing include not only the price of the supply and service, but also transaction costs, namely, coordination and management costs before and after the contract on suppliers.

Li [29] discusses supply chain collaboration and analyses the association between technology assimilation and supply chain collaboration. In their work, the exploitation of technology in collaboration involves using technology to facilitate routine business practices with cost-efficiency. The exploration of technology involves uncovering new methods and models to handle long-term collaboration problems. Mclvor [34] argues that neither transaction cost economics nor the resource-based view alone can fully explain the complexities of outsourcing. A prescriptive framework for outsourcing evaluation is presented which suggest that the outsourcing decision should be made based on contribution to competitive advantage, a firm's relative capabilities position in the area, and the opportunism associated with the outsourcing.

Nonetheless, research on the theory and practice of designing an orchestration network which leverages on the capabilities of different types of firms and resources to make the supply chain more flexible, reliable, and sustainable is scarce. The path for implementing such a SCO is also not well investigated. We propose an orchestration framework, which leverages on both the MNC's international network and LSP capabilities and provides a win-win collaborative platform for all and support local industry upgrading. With the practical framework, MNCs will find it easier to create and manage asset-light, reliable and flexible global SCNs, and the LSPs will improve their resource productivity, upgrade service standards, and enhance their business opportunities.

\section{Research Method}

As the research on SCO is scant, a qualitative approach is taken. A semi-structured interview approach is deemed best as it affords respondents, who are senior representative of the firms, the freedom to share their experience and opinions on the issue of orchestration and the same time allows the researchers to provide focus and scope on the discussion. To understand the need for orchestration, we case interviewed twelve firms and government agencies involved in the SCM industry in Singapore, to draw a representative profile of the landscape in SCO and gauge their response to the application potential of the framework. However, for confidentiality reasons, we are unable to provide details of the profile of the MNCs and the LSPs involved.

While the MNCs are keen to enrich their resource pool and extend their networks, they do not want to invest too heavily on local assets. Instead, they choose to establish platforms such as 4PLs which can integrate their global networks with the LSPs. At the same time, SME LSPs are seeking opportunities to enhance the value of their capacity and access additional resources when their own resources are insufficient. Government agencies are keen to promote the productivity and services of the local industry such as improving the use of transportation resources.

Indeed, creating and maintaining the competitive advantage of industry clusters have always been a major task for the government as Singapore is a business and logistics hub in Asia with a high degree of domestic logistics penetration and dense retailing and manufacturing businesses. One focus is to bring the large organizations and SMEs together to build mutually beneficial relationships, and this was done through the partnerships for capability transformation initiative [35]. Though there are many LSPs, the utilization of local resources is still low. For example, urban freight is fragmented as commented in an interview with the Logistics Service and 
International Partnership Office of SPRING Singapore. As a global hub, business always asks for higher standards and reliability. To build a pro-business and world-class sustainable city, the government faces a challenge on the low productivity of services, inconsistent service standards, inadequate infrastructure, and environmental pollution caused by sub-optimal logistics planning. In a global market, many developing countries trade their products internationally. A few MNCs control a significant portion of global trade and retailing. These firms coordinate the chains that link the developing country producers to advanced country markets. While MNCs may not have the local capability, they can always assign the tasks of local procuring and distribution to smaller local players (LSPs) who are keen to partner with the MNCs.

Our interviews with the LSPs, conducted in 2013, reveal that many LSPs typically have 20 - 30 percent of spare capacity and lack a good way to improve capacity utilization due to the limited business opportunities with customers and the preference of customers to award orders to global players who offer standardized services. Many services of the local logistics industry are not standardized, making it difficult for resource sharing, evaluation, and service selection. Thus, there is a need to develop effective platforms for local industry to share resources, collaborate and align service. A practical framework facilitating SCO is needed for collaboration to better meet customer needs, and improve the productivity and resource usage of local industry.

Second, MNCs have strong motivation and specific needs on orchestration. They have global service networks with facilities in many countries and work with LSPs in different locations to extend this network. While the MNCs' strengths are their extended networks and their capability to manage global resources, they face challenges on the market dynamics, short PLCs, and intense competition on cost and service. MNCs are more inclined to enhance their capability in managing the network than investing in assets. A global 3PL coordinating with local 3PLs could be a successful operating model for operating in an emerging market [36]. For MNCs, the choice is to collaborate with the LSPs to make use of their resources to meet customer needs without investing much locally. To do so, they need orchestration models to link their network with the LSPs and simplify their interface with the LSPs.

Third, LSPs need orchestration as most LSPs are SMEs with limited resources and capacity. They need complementary and resource sharing in operations to meet customer demand. LSPs can enhance their business options by linking up with the brand name service providers to take advantage of the economies of scale. In addition, SME LSPs focus on their particular domains and lack good knowledge on the latest technologies and operations management skills. They need platforms and networks to adapt to innovative models for collaboration/ orchestration between various supply chain functions and players. These platforms and networks may not exist in the market, and need to be created by the joint effort of the orchestrators and the SME LSPs.

This research proposes a practical orchestration framework, which leverages on both the MNCs' international network and LSP capabilities to provide a win-win collaborative platform for all and support the upgrading of the local industry. This exploratory study involves MNCs, LSPs and government agencies. We rely on the literature, semi-structured interviews with the participants, and employ open-ended questionnaires for feedback. The participants are divided as follows:

- 3 MNCs with significant operations in Singapore, mainly in the high-tech sector.

- 1 MNC3PL with operations in Singapore, who service MNCs over multiple industries.

- 8 LSPs in Singapore. They normally focus on some expert areas and serve domestic and international firms. Some of them are subcontractors for foreign 3PLs with their strong local capabilities, knowledge and familiarities with local rules and regulations.

- 1 Government agency_-SPRING Singapore-who is responsible for helping enterprises grow and building trust in Singapore products and services. SPRING help firms in financing, capability and management development, technology and innovation, and market access.

\section{SCO Framework}

An orchestration framework is proposed comprising components such as orchestrated SCN, a relationship model of supply chain actors, a "Win-to-All" pro-orchestration model, and LSP collaboration platforms in key locations as shown in Figure 1. The formation of a globally orchestrated SCN with the features of flexibility, reliability and sustainability is the purpose of the orchestration framework. Flexibility refers to an asset light supply chain which is adaptive and scalable to changes in the market, reliability refers to the high satisfaction rate to customer requirements, and sustainability refers to long-term competitive advantages established through 


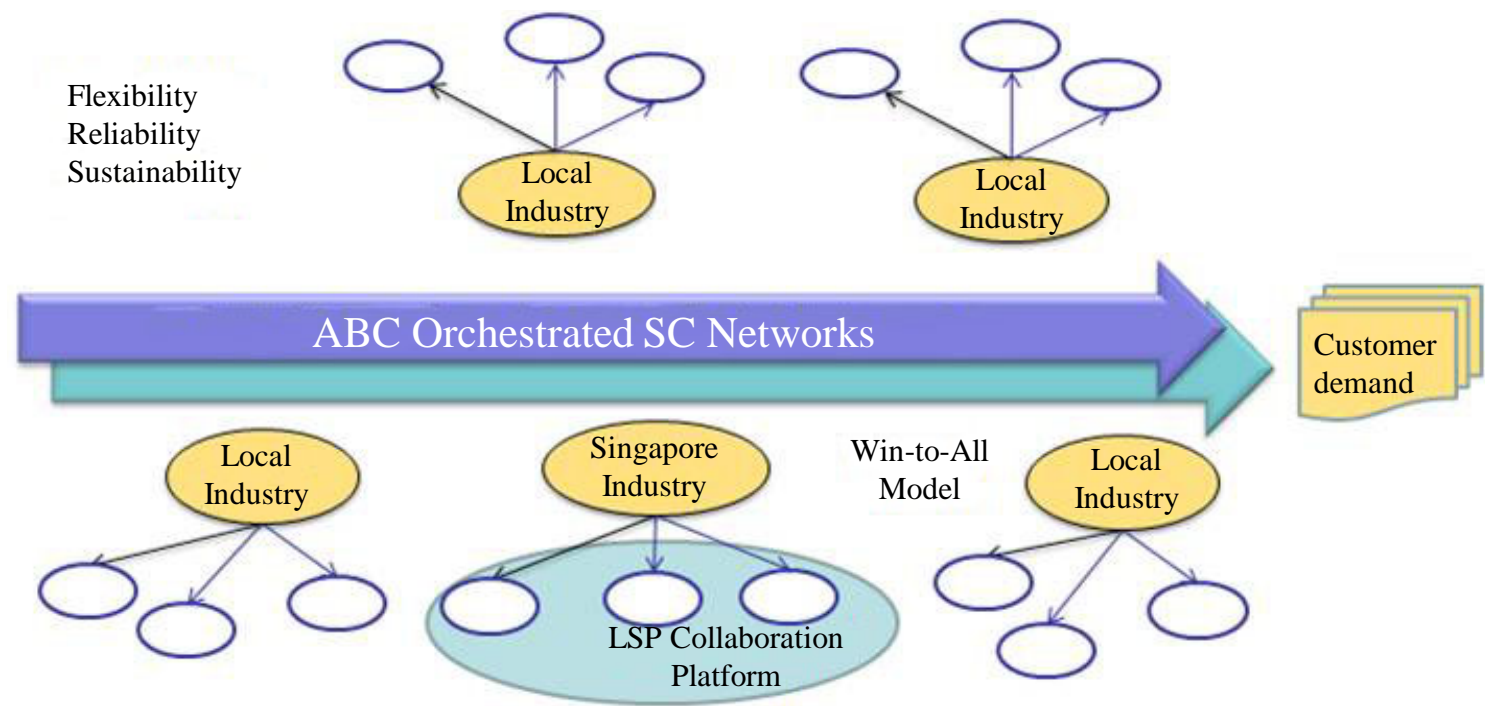

Figure 1. Supply chain orchestration framework.

orchestration. This is supported by multiple local LSPs collaboration platforms which are established through the orchestration of the MNC's local branches and the SME LSPs, and the "Win-to-All" model to MNC, LSPs and local government agencies since a SCN is sustainable only if it is beneficial to all participants.

\subsection{Relationship Model of Supply Chain Actors}

Different relationships exist between the orchestrator and the other actors for value creation. As discussed by [12], the relationship between the firms can range from fair trade to hierarchical control. The governance is based on: 1) The complexity of information and knowledge transfer required to sustain a transaction; 2) the extent to which the information and knowledge can be codified and, therefore, transmitted efficiently and without transaction-specific investment; and 3) the capabilities of the actual and potential suppliers in relation to the requirements of the transaction. On a binary measure of high/low, there are eight combinations. Orchestration covers the relationships from pure fair market to hierarchy control. When transactions are easily codified, product specifications are relatively simple, and suppliers can make the product with little input from the buyers, and fair market is expected. When the ability to codify and the complexity of product specifications are both high and supplier capabilities are low, then the captive type-hierarchy control prevails. Captive suppliers depend on the lead firm for complementary activities such as design, logistics, purchasing, and process technology upgrading. Captive inter-firm linkages control opportunism through the dominance of the lead firm. The pattern of orchestration changes as an industry evolves, and the dynamic nature of orchestration is largely accounted for with the three variables: the complexity of products and services, the ability to code services, and the ability of the suppliers. The orchestrator sets the parameters for the partners and it may have close control or captive relationships with those partners who perform critical functions and hold critical knowledge and key resources of the supply chain based on the long-term agreements or share-holding relationships. The orchestrator has relatively loose relationships, such as fair market and modular relationships, with the LSPs that the orchestrator has little intention to involve directly.

While the interest of MNCs is more on extending the global network and enriching their resource pools, the LSPs are more interested in upgrading service capability and linking to the global market. Although the interests may be different, once they are in the same supply chain, they have a common goal—to improve the competitiveness of the supply chain and to meet the final customer's demands with lower cost and acceptable customer service level. On the interaction between both parties under orchestration, we posit that the interplay is classified into five areas: capability/resource, network, productivity, process, and service standards, as shown in Table 1.

For the MNC, the interplay with the LSPs is the development of supply chain capabilities by enriching their resource pool. First, the capability in terms of flexibility and responsiveness is improved as the local resources provide the support base for the MNC to comply with customer resource requirements. Second, the MNC's 
Table 1. Relationship between MNC and LSPs in SCO.

\begin{tabular}{lll}
\hline \multicolumn{1}{c}{ Area } & \multicolumn{1}{c}{ MNC } & \multicolumn{1}{c}{ LSPs } \\
\hline $\begin{array}{l}\text { Capability/ } \\
\text { resource }\end{array}$ & $\begin{array}{l}\text { Extend knowledge on local resources and policies; } \\
\text { Identify critical resource needed for competitiveness } \\
\text { and sustainability. }\end{array}$ & $\begin{array}{l}\text { Learn from MNC international experience in processes, } \\
\text { specialization, facilitation; enhance capabilities on core } \\
\text { competency. }\end{array}$ \\
Network & $\begin{array}{l}\text { Extend network and increasing resource pool. } \\
\text { Productivity }\end{array}$ & $\begin{array}{l}\text { Join international network and enhance business } \\
\text { opportunities. }\end{array}$ \\
Outsourcing-do more with limited asset investment. & Improve productivity by reducing spare resources. \\
Process & $\begin{array}{l}\text { Improve processes standardization and interfaces. } \\
\text { Outsource and monitor functions and processes. }\end{array}$ & $\begin{array}{l}\text { Improve process based on standardized requirements } \\
\text { from MNC. }\end{array}$ \\
Service standard & $\begin{array}{l}\text { Define and maintain service standards, which may be } \\
\text { affected by local partners. Improve on managing } \\
\text { service standards. }\end{array}$ & \begin{tabular}{l} 
Improve service level by referencing MNC standards. \\
\hline
\end{tabular} \\
\hline
\end{tabular}

network is enhanced and extended with the pooling of resources from multiple locations. Third, the capacity and productivity of the SCN is improved with enhanced service capability. Further, the orchestrator will play a key role for process management with the responsibility on process design, standardization, outsourcing, streamlining, and performance monitoring. Finally, as an orchestrator, it is key to define, maintain, and continuously improve service standards because of outsourcing to the LSPs.

For the LSPs, the challenge comes from limited connection to the global supply chain and lagging in technology, processes and service standards. LSPs have to upgrade their products and services, extend the reaching of their services and find new customers [37]. Orchestration helps such LSPs to handle the above challenge. By joining the MNC's networks, the LSPs can learn from international best practices. The LSPs will get more business opportunities, especially those opportunities that are normally only awarded to global players. The LSP's resource productivity will be improved due to more opportunities and resource sharing through orchestration. Also, the processes and the services of the LSPs will be improved as the integration with the MNC at the business level is finally realized at the process level. This greatly increases the opportunity for the LSPs to improve their process technologies and their supply chain performance. Furthermore, the upgrading of facilities, processes and services normally requires considerable investment which may be inhibited by the limited investment capability of the local firms. The involvement of global MNCs can provide solutions beneficial to the local industry.

\subsection{Orchestrated SCN}

The second part of the proposed framework is the globally orchestrated SCN. The network is the entity to realize SCO. To create an orchestrated network, a few considerations are called for: 1 ) What is the purpose and value of orchestration? 2) How to coordinate the different interests of the actors as the orchestrator are more interested in asset-light networks and controllable service quality and LSPs are interested in enhancing business opportunities and productivity; 3) What is the path for a firm joining an orchestration network?

We assume a global SCN comprising the orchestrator and members (Figure 1), where MNC ABC seeks to set up an orchestrated network, to satisfy the demand of the final customers. The SCN needs to be flexible, reliable and sustainable. While the SCN has multiple locations, MNC ABC may not want to invest heavily on each location because the market is dynamic. This network seeks to achieve SCO: 1) a platform for collaboration between the orchestrator and LSPs where the MNC is the key player who sets the parameters, segment the supply chain and add new actors; 2) a base for identifying, capturing, and integrating value to the orchestrated network through which the orchestrator maintains a resource pool for selection; 3) a base (e.g. benchmarking cases and data) to measure and maintain flexibility, reliability and sustainability of the network.

The orchestrator functions as: 1) architect and design of the supply chain; 2) coordination \& control: control through empowerment and coordination for interdependency management: the orchestrator will balance the work of the actors when it plans the jobs; 3) identification and integration: the orchestrator identifies critical resources for the network and creates value through the integration of resources and services.

Several benefits accrue through the network. First, the orchestrator can gain more resources with little in- 
vestment in infrastructure, and build a SCN based on customer requirements faster. Second, it provides opportunities for the LSPs to involve in the global business. Third, the supply chain is more scalable and flexible in meeting customer needs. Fourth, it lowers the orchestrator's cost by using local resources as it can be more costly to allocate an international resource to a location than having a local resource with the same capability.

\section{3. "Win-to-All" Pro-Orchestration Model}

Though orchestration is between firms, government agencies help to promote orchestration for the purpose of upgrading the local industry. As many SME 3PLs lack the knowledge and capability to adapt to orchestration, government agencies can help them to build the skills and interfaces. Figure 2 shows the pro-orchestration "win-to-all” model. Here, the agencies promote industry upgrading strategies by coordinating with the MNCs and LSPs, and the MNCs and LSPs define their orchestration strategies based on capability, relationships, and interactions.

Figure 2 shows the three interaction areas among the stakeholders. Area 1 represents the common interest and interactions between the MNCs and LSPs, including the business relationships, which lies in the continuum of fair trading and hierarchy control. An orchestrator has the right to choose and define the relationships with the LSPs. Thus, the orchestrator coordinates the activities of the supply chain and sets requirements on complying with standards, improving service quality, adopting specific equipment and processes, purchasing materials from designated vendors, and allocating resources to specific locations. Area 2 represents the interests and interactions between LSPs and government agencies. It includes the daily services in the agencies supporting local enterprises, and the programs for upgrading the skills of the local firms. Government support is not limited to financial support and capability building, but also advisories on policies. Area 3 represents the interests and interactions between international firms and local government agencies. Local industry upgrading can be the focus of the MNCs and government agencies, who can initiate orchestration programs to enable the local industry to comply with international standards and service needs. This accelerates learning.

The critical area of the model is the central part in Figure 2 covered by MNCs, LSPs and government agencies. This is the area of common interest to all actors when working to promote orchestration. It can be a program with an MNC as an orchestrator and with multiple SME LSPs as members and the agency providing policy and financial support. They collaborate to make an orchestrated network work and upgrade the local industry.

\subsection{Collaboration Platform for LSPS}

A trend has been the reduction in the number of supply bases. While LSPs are critical to the local economy and

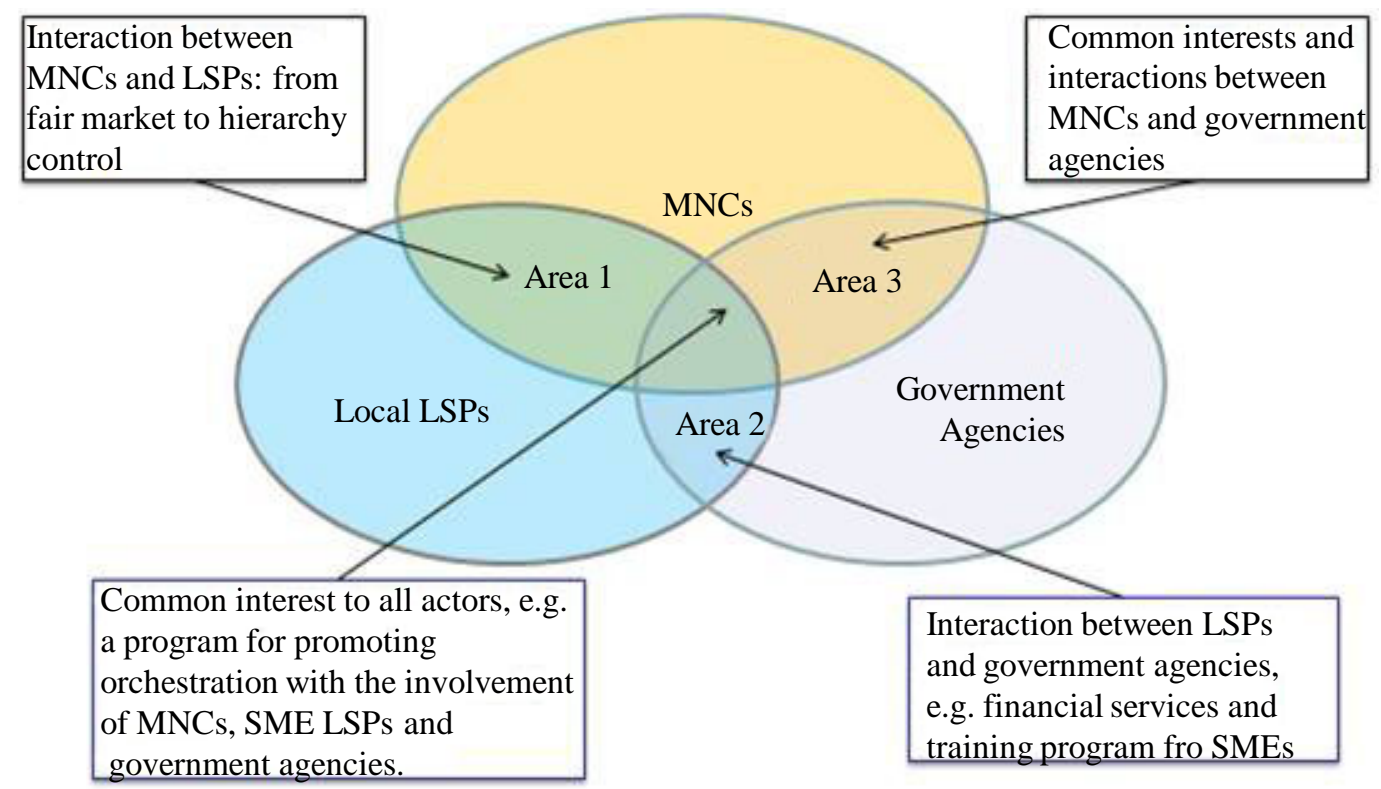

Figure 2. Pro-orchestration “win-for-all” collaboration model. 
have strong expertise and local knowledge, individual LSP may not be credible enough to secure business in the global market due to the limitations in resources and capabilities. A consortium based on collaboration could be a means for LSPs to access larger customers.

Resource sharing has been identified as a necessity for improving productivity in local industry. It can be achieved through a platform which manages the dependencies of resources. The collaboration platforms can play an important role on improving the productivity and maximizing the value of local resources.

To develop themselves and their associated industries, LSPs need collaboration platforms to maintain service standards and integrate with global SCNs. LSPs need to add value to its partners and assume some supply chain responsibility by contributing capabilities and resources. LSPs need a platform to complement partners to upgrade their productivity and service levels of the supply chain. Strong cluster competitiveness is the reason for attracting business to a particular geographical area. Thus, LSPs should form collaboration platforms to increase competitiveness of the local industry.

\section{Approach Strategies to Realizing SCO}

While orchestration is key to effective SCM, the realization of an orchestration outcome depends on a clear approach strategy [8]. The path to realizing SCO includes a few steps related to supporting technologies (Figure 3). First, the orchestration strategy needs to be defined. Next, valuable resources should be identified and cataloged, and pooling technologies could be applied to allocate the right resources to the right segments of the supply chain. Third, resources need to be networked to enhance their interface and value to the market and integration technologies should be applied to align the resource with the supply chain agenda. Fourth, supply and demand should be aggregated and matched optimally in both information and material flows. Finally, an orchestration IT platform needs to be made available.

\subsection{Orchestration Strategy}

In practice, with the increasing complexity in products and services and demand dynamics, supply chains tend to be in a captive model and this raises the need for lead firms to be orchestrators. There has to be a common agenda for orchestration to drive the achievement of the supply chain goals [7]. An orchestration strategy needs to be subscribed by all entities in the chain. The orchestrator is responsible for the design of the strategy and agenda. Other actors would continuously optimize their position in the chain to achieve better control and collaboration with upstream and downstream partners.

The orchestrator should be quick to define a supply chain based on customer needs, design and divide the supply chain based on product/service features, and identify the resources needed to deliver the highest value to the chain. One approach is to use the order decoupling point to perform an orchestration differentiation to customer demands as shown in Figure 4. The decoupling point separates the part of the supply chain whose plans are governed by customer orders (pull process) from the part of the supply chain whose plans are based on demand forecasts (push process) [14]. Downstream of the decoupling point, the focus is on customer responsiveness through lead time and flexibility. Upstream, towards the suppliers, the focus is on efficiency by employing larger batch sizes. Different strategies can be applied on different customers and products by jointly applying decoupling and postponement.

\subsection{Resource Pooling for Orchestration}

Once the strategy is defined, the next step is to identify the resource candidates for the different segments of the supply chain. An orchestrator should have a pool of resources where every segment can have multiple candidate resources so the supply chain can be optimally configured.

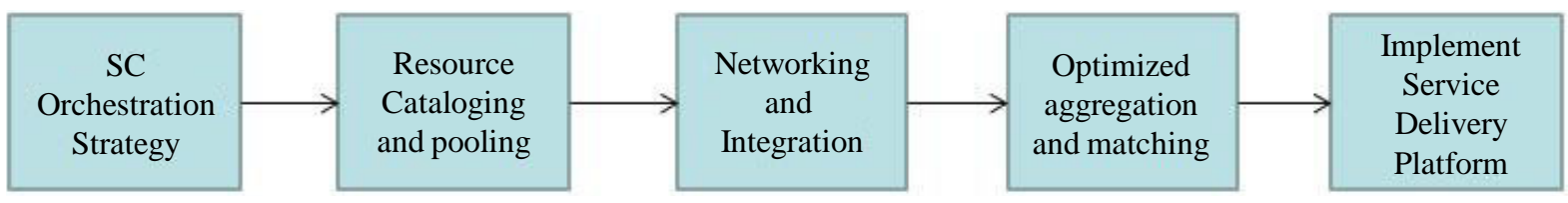

Figure 3. Path for realizing SCO. 


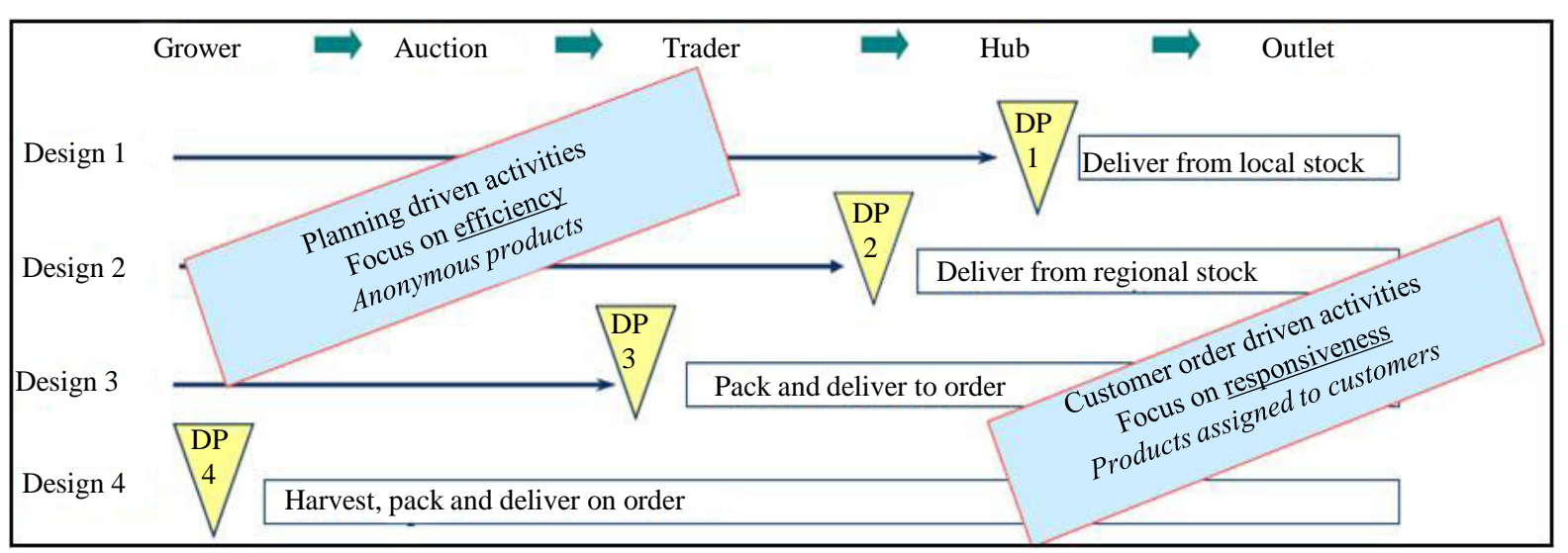

Figure 4. Orchestration strategy and decoupling point [14] (van der Vorst, 2007).

Resource pooling is the grouping of resources to maximize advantage and minimize risk to the users [38]. An orchestrator may have pools of resources and each segment of a supply chain can have multiple resources. Resource pooling can be applied to improve supply chain reliability and flexibility and enhance productivity. An orchestrator can design the mechanism for resource pooling, allocate and pool resources to the right segments of the supply chain. This offers some benefits. First, it increases the reliability against failure by pooling of alternative resources and is easier to find replacements for missing resources. Second, it helps to maintain supply chain flexibility and resilience for handling surges in resource requirements. The supply chain can function more capably even when the actual demand-supply matrix differs substantially from that envisaged by the network designers.

\subsection{Networking and Integration}

The value of orchestration comes from the networking and integration of services and resources. As the process of disintegration and reintegration continues, emerging aggregate players will become firms of the future [2]. These actors will bring innovation and efficiency to the network by orchestrating the flow of goods, enterprise information, and funds between them. So, an orchestrator has to be a networking facilitator and integrator with innovation capabilities to produce (together with supply chain partners) the products and services for customers. Competition is between SCNs and will center on the orchestrated network.

While integration put things together to create value, networking extends the reach of the orchestrator and local resources and makes the resources and services available for integration. The "network effect" whereby a resource or service becomes more valuable as more people use it, thereby encouraging more adopters. When the network effect presents, the value of a product or service is dependent on the number of others using it. So, a network extends the value of the resource and improves the productive use of the resource as more users can access this resource. This provides more opportunities for the resource and enhances its value. This is useful in improving the value of logistics and production resources. To the orchestrator, the network effect reduces the risk of resource shortage, and increases the opportunity of resource pooling [9].

\subsection{Optimal Aggregating and Matching}

Demand and supply relationships exist between all segments of a SCN. Aggregating demand and supply consolidates the requirements and uses resources more economically, say, consolidating the supply bases and distribution facilities. Optimized matching of demand and supply can then happen.

With the variations in supply and demand, an orchestrator is key in cataloging, aggregating, and matching supply to demand. From Figure 5, before orchestration, suppliers deliver directly to customers in the required amounts and time, or customers may pick and pack on their own. In anorchestrated scenario, the supplies and demands are optimally consolidated and cataloged on an orchestration platform, which supports simulation for optimal decision making. While Singapore is ranked high on logistics and its service standard and quality are accepted as good, herlogistics services are still fragmented. For example, the LSPs provide their services in 

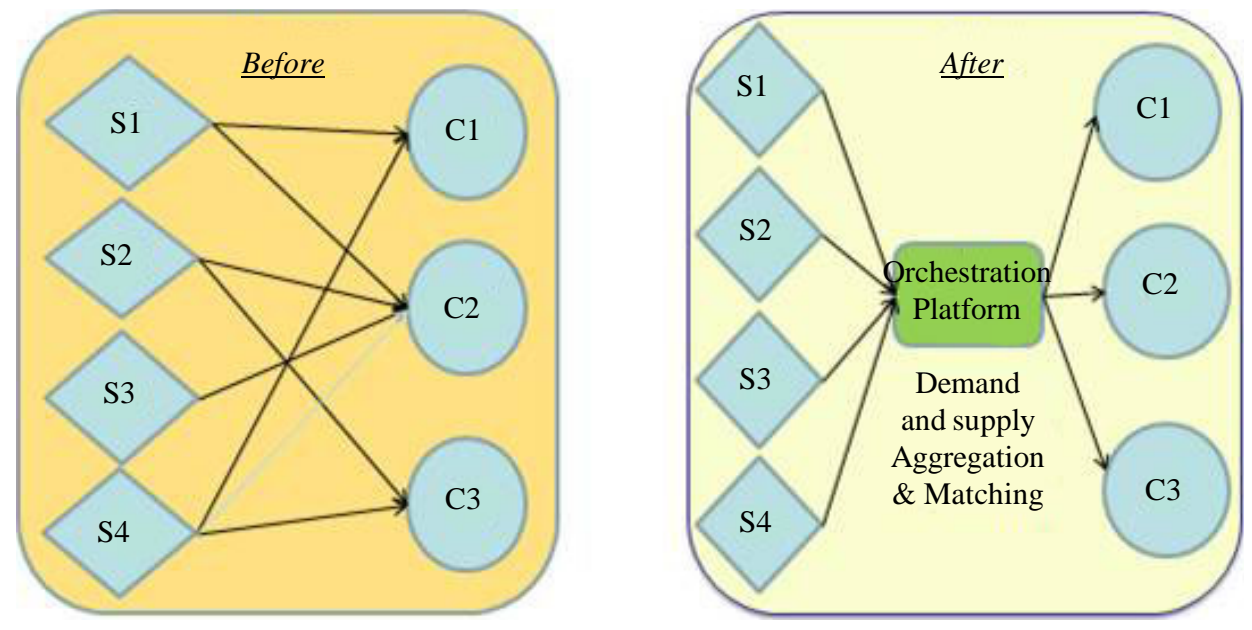

Figure 5. Demand and supply aggregating and matching in supply chains.

non-shared facilities (most are self-owned) and they still need to improve on cost-efficiency and service. One way is to build a base for common logistics services and consolidate these services.

\subsection{Service Delivery IT Platform}

Software-As-Service (SaaS) and cloud-based deployments, on-demand offerings now extend to supply chain services. Enterprise IT integrates business functional areas and links suppliers and customers of the entire supply chain and e-solutions are necessary for a supply chain to improve collaboration to compete in the global market [29]. To be an innovative supply chain practice, orchestration needs to be established as an enterprise IT service base for supply chain configuration, sharing, and execution. The orchestration platform is not only a base for orchestration, but also the platform supporting the delivery of products and services. As shown in Figure 6, the orchestration IT platform provides integrated views of the data including the management of supply and demand information, the resources information of the suppliers, customers, and LSPs. Semantics representation of supply chain queries and information can improve the relevance of the data and improve the quality of partner selection and the organization of the SCN for efficiency [39].

Data availability and the logic of decision making are two sides of the same coin [40]. To support orchestration, the platform will have four functions: integrated data management, optimized aggregating and matching, and integrated delivery management, and integrated relationship management. As a central platform to support orchestration, data management covering enterprise information alignment and integration is a critical function. The platform will have three integrated data-views of supply, demand and resources. Supply and demand aggregating and matching needs to be realized in the platform. An integrated service delivery is critical for orchestration as it enables publishing and brokering business services and allows these to be repurposed, traded and consumed in the supply chain. Further, the relationship models of actors discussed earlier need to be realized as an integrated relationship management function which is pro-orchestration and is different from the traditional relationship model.

\section{Application Potential and Benefits}

\subsection{Scenario 1-MNC Network + LSPs}

MNC1 is a well-known global logistics firm with a broad service network which helps the MNC1 to acquire large customer accounts. It does not have a full set of resources to fulfill all the service needs of customers when entering into emerging markets. It opts to outsource the low value-adding activities to its LSPs, as suggested in the literature by Glagola [23]. It builds multiple connections with the LSPs who provide complementary services based on their local capabilities and low-cost advantages. The LSPs (often SMEs) serve as the first tier partners of MNC1. The outsourced activities include transportation, warehousing, and freight forwarding. By linking to MNC1, the LSPs receive new business and benefit from the brand of MNC1. With the current practice of MNC1, 


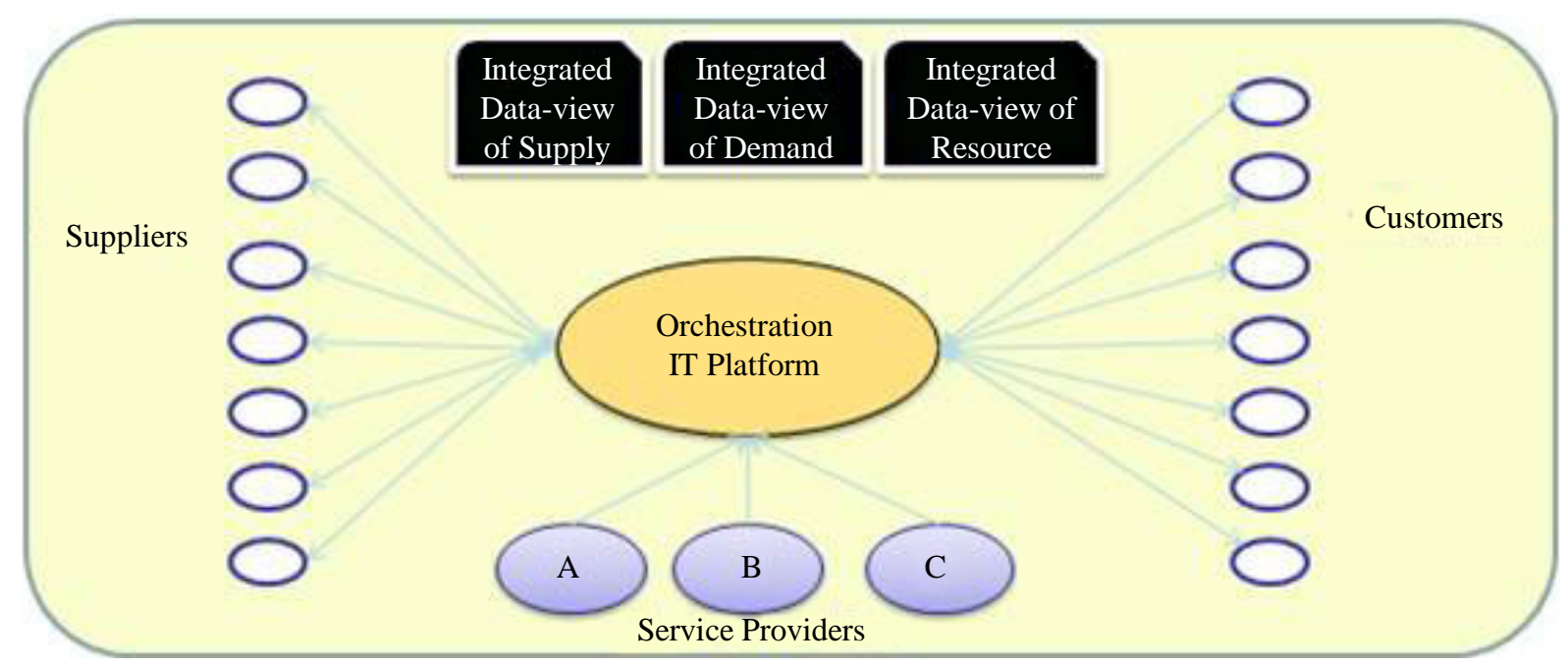

Figure 6. SCO enterprise IT platform.

the services of the LSPs are not integrated with that of MNC1 and the operations between MNC1 and the LSPs are not orchestrated.

A solution is proposed to build an effective orchestration and empowerment platform to maintain the flexibility and reliability of the SCN and make better use of the LSPs' resources. MNC1 and the LSPs' supply chain operations are networked. For this, the LSPs' capabilities need to be upgraded to remain relevant and integrated with the services of MNC1. An enterprise based IT platform which supports SCO and service delivery should be established [5]. The LSPs focus on their domain and try to establish their reputation in their areas.

The value propositions of this application example(see Table 2) are that: 1) MNC1 can focus on customer engagement and services, leaving the local services to the LSPs through the orchestration platform; 2) The LSPs provide cost-efficient local services to complement with MNC's services to their customers; 3) The LSPs can leverage on the brand of the MNCs and reach more customers via the orchestration platform; 4) The MNC works not only with LSPs but also with the government agencies to facilitate collaboration with local industry; 5) The flexibility of the supply chain is improved due to better interfaces to LSPs and the sustainability is expected to be improved due to MNC1's focus on customer value.

\subsection{Scenario 2-Resource Sharing among Local 3PLs}

Local 3PLs, the LSPs in logistics industry, normally work on specific areas with limited resources and lack economies of scale. So the operating costs of the 3PLs are relatively higher leading to lower productivity. Most of them lack effective approaches on improving resource utilization and sharing [34]. This results in idle resources at times and shortage of resources to commit to jobs at other times. The smaller 3PLs seldom outsource their jobs to other 3PLs if they lack capability/capacity, and customers avoid assigning big orders to these 3PLs who have capacity limitation and lack good service standards.

An orchestration platform can benefit the small 3PLs, especially on resource (trucks, prime movers) and enterprise knowledge sharing among the 3PLs. The orchestration platform can be built by a consortium of LSPs or leading firms with support from government agencies initially. Members of the platform can play orchestrator roles for the orders that they have secured and organize their own resource pool based on the resources linked to the platform. By deploying the orchestration platform, the standardization of services, service level and pricing can be achieved and improved. This will upgrade the local industry. The shortcoming of this model is that the involvement of global players is limited, stunting local industry upgrading.

The value proposition of this application (Table 2) is that: 1) LSPs can increase capacity without increasing their actual resources; 2) They can also increase resource utilization by sharing their spare resources with organizations that need more resources. In this way, the productivity of the entire logistics sector can be improved as wastage of spare resources is reduced; 3) LSPs can increase their negotiation (bargaining) power while they are doing business with some large customers and this may increase their business opportunities; 4) the flexibility and sustainability of the industry sector are expected to be improved. 
Table 2. Value propositions of the scenarios.

\begin{tabular}{|c|c|c|c|c|}
\hline & Scenario 1 & Scenario 2 & Scenario 3 & Scenario 4 \\
\hline Value creation & $\begin{array}{l}\text { MNC } 1 \text { can focus on } \\
\text { customer engagement and } \\
\text { value }\end{array}$ & $\begin{array}{l}\text { More opportunities for } \\
\text { LSPs due to better } \\
\text { bargaining power }\end{array}$ & $\begin{array}{l}\text { MNC2 can focus on } \\
\text { customer issues with the } \\
\text { help of } 4 \mathrm{PL}\end{array}$ & $\begin{array}{c}\text { MNC3 can focus on } \\
\text { production and customer } \\
\text { value }\end{array}$ \\
\hline $\begin{array}{c}\text { Resource } \\
\text { dependency }\end{array}$ & $\begin{array}{l}\text { MNC1 reduces local } \\
\text { asset and dependency on } \\
\text { local resources through } \\
\text { standardized interfaces. }\end{array}$ & $\begin{array}{l}\text { Resource dependency is } \\
\text { reduced due to the } \\
\text { improved availability of } \\
\text { resources }\end{array}$ & $\begin{array}{l}\text { Decoupling local } \\
\text { resources through the } \\
\text { 4PL }\end{array}$ & $\begin{array}{l}\text { MNC3 decouples from } \\
\text { managing the inventories } \\
\text { from multiple suppliers }\end{array}$ \\
\hline Transaction cost & $\begin{array}{l}\text { Reduce service cost by } \\
\text { local resources and } \\
\text { coordination cost by } \\
\text { standard platform }\end{array}$ & $\begin{array}{l}\text { Cost saving by resource } \\
\text { sharing and improve } \\
\text { resource utilization }\end{array}$ & $\begin{array}{l}\text { Simplify interface to } \\
\text { LSPs to reduce } \\
\text { coordination cost }\end{array}$ & $\begin{array}{l}\text { Reduce coordination cost } \\
\text { (with suppliers) and } \\
\text { inventory and } \\
\text { obsolescence costs }\end{array}$ \\
\hline $\begin{array}{c}\text { Flexibility and } \\
\text { scalability }\end{array}$ & $\begin{array}{l}\text { Flexibility and scalability } \\
\text { improved with less assets } \\
\text { and standardized } \\
\text { interfaces to LSPs }\end{array}$ & $\begin{array}{c}\text { More flexible and } \\
\text { scalable in resources and } \\
\text { can handle bigger orders } \\
\text { using partner resources }\end{array}$ & $\begin{array}{l}\text { More flexible to secure } \\
\text { local resources }\end{array}$ & $\begin{array}{c}\text { More flexible and scalable } \\
\text { with 3PL managing the } \\
\text { inventories }\end{array}$ \\
\hline $\begin{array}{c}\text { Reliability and } \\
\text { sustainability }\end{array}$ & $\begin{array}{c}\text { Reliability is neutral } \\
\text { Sustainability improved } \\
\text { due to higher value-add }\end{array}$ & $\begin{array}{l}\text { Reliability is neutral; } \\
\text { Sustainability improved } \\
\text { due to more business }\end{array}$ & $\begin{array}{l}\text { Low reliability due to use } \\
\text { of external 4PL. } \\
\text { Sustainability improved } \\
\text { due to more } \\
\text { customer-focus and } \\
\text { opportunities }\end{array}$ & $\begin{array}{c}\text { Less reliable inventory } \\
\text { control due to outsourcing; } \\
\text { Sustainability improved } \\
\text { due to focus on core } \\
\text { business }\end{array}$ \\
\hline
\end{tabular}

\subsection{Scenario 3-4PL Orchestration with SME 3PLS}

MNC2 is a global manufacturer who outsources its logistics operations. Much effort and time are spent on coordinating with multiple LSPs due to the complexity of its products and operations. Simplifying the interfaces is critical to improve the efficiency and effectiveness of the coordination with the LSPs and to better MNC2's overall performance.

A solution is a 4PL (Fourth Party Logistics Provider) orchestration model where the 4PL acts as a local orchestrator who interfaces with MNC2's global network and provides services on managing the local 3PLs. To avoid any conflicts of interest, the 4PL should ideally not operate 3PL services but act as an in-house service manager of its customers. Some MNCs have started implementing the 4PL model to streamline their resources. There are some challenges in the implementation of the 4PL orchestration model based on the interviews. First, there is a lack of local 4PLs and it is necessary to raise the awareness of the 4PL model. Second, there is a lack of neutral 4PLs. 4PLs should be independent and not compete with the 3PLs. Third, some 4PLs are IT firms who lack domain knowledge, 4PL capabilities and operating experience [20].

The value proposition of this model (Table 2) is that: 1) MNC2 is free from the time/effort consuming activities of managing multiple 3PLs; 2) Its customers only deal with the 4PL as a one-stop service provider; 3 ) The 4PL acts as a supply chain expert and consults customers on supply chain operations; They manage the 3PLs more effectively and report the consolidated performance to customers. The coordination and logistics costs should decrease; 4) the supply chain is more flexible but the reliability depends on the quality of the 4PL; 5) Sustainability will improve due to MNC2's focus on core competencies.

\subsection{Scenario 4-3PL Services for Inventory Management}

Due to the lack of an accurate forecasting solution, an international original equipment manufacturer (OEM) MNC3 holds buffer stock and bears a high carrying cost and a high obsolescence cost of parts. Additional manpower and resources are used to manage these inventories which do little to value-adding production and distribution activities. Some inventories are accumulated due to incorrect demand information and poor coordination in managing the components, which are related to the final product.

While OEMs such as MNC3 can outsource their stock management to local SME LSPs directly, they are concerned about the capacity, quality and security of the services provided by the LSPs. One solution is that MNC3 outsources its inventory management to an MNC 3PL or a local leading 3PL. These relatively large players act as orchestrators and take the responsibility of managing the local SME resources. The orchestrator is 
selected based on experience and reputation.

The value propositions of this model (Table 2) are: 1) MNC3 can focus on its core business of production rather than stock control; 2) An LSP 3PL manages multiple suppliers and consolidate parts for the OEM and this can simplify the interfaces and reduce coordination cost; 3) Better stock control due to stock pooling and the orchestrator's experience and capability in stock control; 4) Improved flexibility due to simplified interfaces; 5) Reliability can be reduced due to the outsourcing of inventory control. This enlarges the job scope of the 3PL [15].

\subsection{Implication and Discussion}

Our approach in this paper is to provide a practical bent to building a seamless global supply chain operations notably in the area of supply chain coordination between the orchestrator and the other actors. This is a critical issue as most research tend to be theoretical in approach without providing due consideration to the motives and nature of the LSPs, MNCs, and government intervention [27]. Based on the above approach strategies, several implications for orchestration arise.

Create value through customer-centric and integration. An orchestrator should have an in-depth understanding of customer needs and possess the capability to identify and create value for the supply chain [19]. As a supply chain is dynamic, the orchestrator needs to identify valuable and critical resources and integrate them to create a competitive supply chain. This makes better use of the resources and integrated services can be generated and provided to customers.

Light ownership of assets for orchestrators. The orchestrator focuses on designing and managing the SCN. Its strength is on network orchestration and resource management. It provides effective supply chain services but it does not bear the risk of owning an asset intensive supply chain, as suggested by [11].

Supply chain segmentation. Firms should focus on core competencies to maintain competitive advantage. Two competencies are key: product/service differentiation and cost efficiency. Based on this, segmentation and modularization are critical differentiation strategies to be applied to supply chains. Orchestration is needed for the effective realization of the segmentation and differentiation strategies.

Flexibility and scalability. Market and customer demands are dynamic. Flexibility is important to supply chains with changes in product type, location, service time, and product quantity. An orchestrator should be able to maintain supply chain flexibility by managing a pool of resources and forming scalable enterprise networks to adapt to these dynamics.

Reliability and sustainability. Reliability is a critical feature of a supply chain. A breakdown in part of a supply chain may lower supply chain performance. Resource pooling in orchestration improves supply chain reliability by providing multiple routes and resources alternatives and hence mitigate supply chain risk. Sustainability can be improved due to more customer-focused, more business and improved reliability.

\section{Conclusions}

In the networked collaboration between enterprises, the success of such operations is indeed more complex than presented thus far and the trends are much broader. This paper recognizes the value of leveraging on the global network of the MNC and the local resources of the LSPs to realize SCO. While MNCs build orchestrated and asset-light SCNs by integrating multiple resources, government and LSPs have roles in SCO to improve productivity, upgrade industry and enhance the value of local resources. This paper contributes to the theory and practice of SCO. First, it enriches our understanding on the influence of supply chain governance, outsourcing and resource dependency on SCO. Second, a practical orchestration framework which leverages on an MNC's network and LSP capabilities at a strategic level is proposed for value-creation, resource efficiency, flexibility, reliability and sustainability of the chain. Next, some approach strategies are proposed for realizing orchestration, which recognizes capabilities and technology needs.

From the literature and case interviews of the MNC and the LSPs, an orchestration framework is proposed. The approach leverages on the MNC's SCN and local resource capabilities by identifying and integrating multiple resources into the SCN. A pro-orchestration collaborative model between MNCs, LSPs, and government agencies is proposed. We highlight some approach strategies for realizing orchestration, specifically the MNC network + LSPs, MNC network + 4PL model, and local SME consortium, and leading 3PL as orchestrator. We recognize our limitations too. Namely, the context is specific to a country albeit with global connectivity in lo- 
gistics and business. Second, we are only working with ten firms, making our conclusions somewhat guarded. Future work will focus on modeling and the technology issues of orchestration such as an orchestrated service delivery platform, optimized demand/supply aggregation and matching, and resource pooling methods, including the human resources and tight talent pool. We can also extend the work to other countries in an emerging market context.

\section{References}

[1] Fung, V.K., Fung, W.K. and Wind, Y. (2007) Competing in a Flat World. ANGLAIS, Langue.

[2] Ritran, G.R., Gurumurthi, S. and Sam, S.L. (2006) Emerging Trends in Supply Chain Governance. MIT Working Paper.

[3] Menychtas, A., Gatzioura, A. and Varvarigou, T. (2011) A Business Resolution Engine for Cloud Marketplaces. IEEE Third International Conference on Cloud Computing Technology and Science (CloudCom), 29 November-1 December 2011, 462-469. http://dx.doi.org/10.1109/cloudcom.2011.68

[4] Hinterhuber, A. (2002) Value Chain Orchestration in Action and the Case of the Global Agrochemical Industry. Long Range Planning, 35, 615-635. http://dx.doi.org/10.1016/S0024-6301(02)00160-7

[5] Hoogeweegen, M.R., Teunissen, W.J.M., Vervest, P.H.M. and Wagenaar, R.W. (1999) Modular Network Design: Using Information and Communication Technology to Allocate Production Tasks in a Virtual Organization. Decision Sciences, 30, 1073-1103. http://dx.doi.org/10.1111/j.1540-5915.1999.tb00919.x

[6] Craig, T. (2005) Outsourcing Offshore Supply Chain Management: What It Is and What It Isn't. http://www.webpronews.com/

[7] Christopher, M. (2010) Logistics and Supply Chain Management. Financial Times/Prentice Hall.

[8] Chang, S.-J. and Park, S.H. (2012) Winning Strategies in China: Competitive Dynamics between MNCs and Local Firms. Long Range Planning, 45, 1-15. http://dx.doi.org/10.1016/j.lrp.2011.11.002

[9] Liebowitz, S.J. and Margolis, S.E. (1994) Network Externality: An Uncommon Tragedy. The Journal of Economic Perspectives, 8, 133-150. http://dx.doi.org/10.1257/jep.8.2.133

[10] Harrington, L. (2014) The Resilent Supply Chain. DHL Supply Chain.

[11] Wind, Y.J., Fung, V. and Fung, W. (2009) Network Orchestration: Creating and Managing Global Supply Chains without Owning Them. The Network Challenge: Strategy, Profit, and Risk in an Interlinked World, 299.

[12] Gereffi, G., Humphrey, J. and Sturgeon, T. (2005) The Governance of Global Value Chains. Review of International Political Economy, 12, 78-104. http://dx.doi.org/10.1080/09692290500049805

[13] Rodon, J., Busquets, X. and Christiaanse, E. (2005) Orchestration in ICT-Enabled Business Networks: A Case in the Repairs Industry. 18th Bled eConference eIntegration in Action, Bled.

[14] van der Vorst, J., Duineveld, M.P., Scheer, F.-P. and Beulens, A.J. (2007) Towards Logistics Orchestration in the Pot Plant Supply Chain Network. Electronic Proceedings of the Euroma 2007 Conference, 18-20 June 2007, Ministry of Economic Affairs, Ankara, 1-10.

[15] Nalla, V.R., Omta, S.W.F., Fortuin, F.T.J.M. and Nalla, R. (2010) Orchestration in Global Agrifood Networks—Future Research Directions Based on the Case of Olam. The 9th Wageningen International Conference on Chain and Network Management.

[16] Zacharia, Z.G., Sanders, N.R. and Nix, N.W. (2011) The Emerging Role of the Third-Party Logistics Provider (3PL) as an Orchestrator. Journal of Business Logistics, 32, 40-54. http://dx.doi.org/10.1111/j.2158-1592.2011.01004.x

[17] Scott, A.J. (1996) Regional Motors of the Global Economy. Futures, 28, 391-411. http://dx.doi.org/10.1016/0016-3287(96)00016-X

[18] Porter, M.E. and Wayland, R.E. (1995) Global Competition and the Localization of Competitive Advantage. Advances in Strategic Management, 11, 63-105.

[19] Ko, S. and Loo, G. (2009) Li \& Fung: Growth for a Supply-Chain Specialist. Asia Case Research Centre, University of Hong Kong, Pokfulam.

[20] Bolumole, Y.A. (2001) The Supply Chain Role of Third-Party Logistics Providers. The International Journal of Logistics Management, 12, 87-102. http://dx.doi.org/10.1108/09574090110806316

[21] Hertz, S. and Alfredsson, M. (2003) Strategic Development of Third Party Logistics Providers. Industrial Marketing Management, 32, 139-149. http://dx.doi.org/10.1016/S0019-8501(02)00228-6

[22] Yilmaz, A. and Bedük, A. (2014) Evaluation of the Effect of the Outsourcing on Resource Dependency and Transaction Cost Approach: A Research in Konya Oiz, Turkey. Procedia—Social and Behavioral Sciences, 109, 737-752. 
http://dx.doi.org/10.1016/j.sbspro.2013.12.538

[23] Lankford, W.M. and Parsa, F. (1999) Outsourcing: A Primer. Management Decision, 37, 310-316. http://dx.doi.org/10.1108/00251749910269357

[24] Glagola, J.R. (2001) Outsourcing: Opportunities and Challenges for Corporate Competitiveness-Part 2. Journal of Corporate Real Estate, 3, 260-269. http://dx.doi.org/10.1108/14630010110811625

[25] Hsiao, H., Van der Vorst, J. and Omta, S.W.F. (2006) Logistics Outsourcing in Food Supply Chain Networks: Theory and Practices. 7th International Conference on Management in AgriFood Chains and Networks, Ede, 31 May-2 June 2006, 135-150.

[26] Koppius, O. and van Heck, E. (2005) Supply and Demand Driven Coordination in Smart Business Networks. In: Vervest, P., van Heck, E., Pau, L.-F. and Preiss, K., Eds., Smart Business Networks, Springer, Berlin, 273-287.

[27] Artuner, C.G. and Anil, I. (2012) Motives for Joint Ventures between Turkish Casting Industry Firms and Their Foreign Partners: An Evaluation from the Perspective of Resource Dependence Theory and Competing Views. Marmara University Suggestion Magazine, 37, 31-49.

[28] Christopher, M. and Peck, H. (2004) Building the Resilient Supply Chain. The International Journal of Logistics Management, 15, 1-14. http://dx.doi.org/10.1108/09574090410700275

[29] Li, L. (2012) Effects of Enterprise Technology on Supply Chain Collaboration: Analysis of China-Linked Supply Chain. Enterprise Information Systems, 6, 55-77. http://dx.doi.org/10.1080/17517575.2011.639904

[30] Hillman, A.J., Withers, M.C. and Collins, B.J. (2009) Resource Dependence Theory: A Review. Journal of Management, 35, 1404-1427. http://dx.doi.org/10.1177/0149206309343469

[31] Malone, T.W. and Crowston, K. (1994) The Interdisciplinary Study of Coordination. ACM Computing Surveys (CSUR), 26, 87-119. http://dx.doi.org/10.1145/174666.174668

[32] Li, Z., Kumar, A. and Lim, Y.G. (2002) Supply Chain Modelling-A Co-Ordination Approach. Integrated Manufacturing Systems, 13, 551-561. http://dx.doi.org/10.1108/09576060210448134

[33] Murray, J.Y. and Kotabe, M. (1999) Sourcing Strategies of U.S. Service Companies: A Modified Transaction-Cost Analysis. Strategic Management Journal, 20, 791-809. http://dx.doi.org/10.1002/(SICI)1097-0266(199909)20:9<791::AID-SMJ49>3.0.CO;2-U

[34] McIvor, R. (2009) How the Transaction Cost and Resource-Based Theories of the Firm Inform Outsourcing Evaluation. Journal of Operations Management, 27, 45-63.

[35] SPRING (2014) Developing Capabilities for Business Growth. SPRING, Singapore.

[36] Langley, J. and Capgemini (2012) The State of Logistics Outsourcing - 2012 Third-Party Logistics: Results and findings of the 16th Annual Study. Capgemini Consulting, US.

[37] Humphrey, J. and Schmitz, H. (2000) Governance and Upgrading: Linking Industrial Cluster and Global Value Chain Research. Institute of Development Studies, Brighton.

[38] Simchi-Levi, D. (2013) Operations Rules: Delivering Customer Value through Flexible Operations. 2nd Edition, MIT Press, Cambridge.

[39] Zdravković, M., Panetto, H., Trajanović, M. and Aubry, A. (2011) An Approach for Formalising the Supply Chain Operations. Enterprise Information Systems, 5, 401-421. http://dx.doi.org/10.1080/17517575.2011.593104

[40] Exon-Taylor, M. (1996) Enterprise management-The Logical Integration of the Supply Chain. Logistics Information Management, 9, 16-21. http://dx.doi.org/10.1108/09576059610113232 


\section{Submit or recommend next manuscript to SCIRP and we will provide best service for you:}

Accepting pre-submission inquiries through Email, Facebook, LinkedIn, Twitter, etc.

A wide selection of journals (inclusive of 9 subjects, more than 200 journals)

Providing 24-hour high-quality service

User-friendly online submission system

Fair and swift peer-review system

Efficient typesetting and proofreading procedure

Display of the result of downloads and visits, as well as the number of cited articles

Maximum dissemination of your research work

Submit your manuscript at: http://papersubmission.scirp.org/ 